\title{
Malignant Peripheral Nerve Sheath Tumors with $t(X ;$ 18). A Pathologic and Molecular Genetic Study
}

Maureen J. O’Sullivan, Michael Kyriakos, Xiaopei Zhu, Mark R. Wick, ${ }^{1}$ Paul E. Swanson, Louis P. Dehner, Paul A. Humphrey, John D. Pfeifer

L.V. Ackerman Laboratory of Surgical Pathology, Washington University Medical Center,

St. Louis, Missouri.

Spindle cell sarcomas often present the surgical pathologist with a considerable diagnostic challenge. Malignant peripheral nerve sheath tumor, leiomyosarcoma, fibrosarcoma, and monophasic synovial sarcoma may all appear similar histologically. The application of ancillary diagnostic modalities, such as immunohistochemistry and electron microscopy, may be helpful in the differentiation of these tumors, but in cases in which these adjunctive techniques fail to demonstrate any more definitive evidence of differentiation, tumor categorization may remain difficult. Cytogenetic and molecular genetic characterization of tumors have provided the basis for the application of molecular assays as the newest components of the diagnostic armamentarium. Because the chromosomal translocation $t(X ; 18)$ has been observed repeatedly in many synovial sarcomas, it has been heralded as a diagnostic hallmark of synovial sarcoma. To formally test the specificity of this translocation for the diagnosis of synovial sarcoma, RNA extracted from formalin-fixed, paraffin-embedded tissue from a variety of soft tissue and spindle cell tumors was evaluated for the presence of $t(X ; 18)$ by reverse transcriptasepolymerase chain reaction. Although $85 \%$ of the synovial sarcomas studied demonstrated $t(X ; 18)$, $75 \%$ of the malignant peripheral nerve sheath tumors in our cohort also demonstrated this translocation. We conclude that the translocation $t(X ; 18)$ is not specific to synovial sarcoma and discuss the implications of the demonstration of $t(X ; 18)$ in a majority of malignant peripheral nerve sheath tumors.

Copyright () 2000 by The United States and Canadian Academy of Pathology, Inc.

VOL. 13, NO. 11, P. 1253, 2000 Printed in the U.S.A.

Date of acceptance: June 27, 2000.

${ }^{1}$ Present address: Division of Surgical Pathology, University of Virginia Medical Center, Box 214, Charlottesville, VA 22908.

Address reprint requests to: John D. Pfeifer, L.V. Ackerman Laboratory of Surgical Pathology, Campus Box 8118; 660 S. Euclid Ave., St. Louis, MO 63110; phone: 314-747-0276; fax: 314-362-8950; E-mail: pfeifer@ path.wustl.edu.
KEY WORDS: Chromosomal translocation; malignant peripheral nerve sheath tumor; specificity; synovial sarcoma; $t(X ; 18)$.

Mod Pathol 2000;13(11):1253-1263

Spindle cell sarcomas include a wide variety of tumors, some of which, such as synovial sarcoma (SS) and malignant peripheral nerve sheath tumor (MPNST), may have overlapping histologic features. Because SS has classically been recognized as a neoplasm arising in the juxta-articular peripheral soft tissue in adolescents or young adults (1-6), and MPNST has been associated with peripheral nerves, especially in persons with neurofibromatosis (NF1), clinical features have often been used as a means to discriminate between the two tumors. However, clinical features have become less diagnostically valuable with the documentation of SS inpatients of a wider age range and in a greater diversity of anatomic sites (7-14). Notably, putative examples of both mono- and biphasic SS have been described within, and in association with, major nerves (15-19).

The immunophenotypic overlap between MPNST and SS has further confounded their differential diagnosis. Although SS is classically considered to express the epithelial markers cytokeratin (CK) and epithelial membrane antigen (EMA), whereas MPNSTs classically express the neural markers S-100 protein and CD57, a significant percentage of cases show immunophenotypic overlap such that a subgroup of MPNSTs express EMA and CK and a proportion of SSs express S-100 and CD57 (20-27). Similarly, even though electron microscopy may be helpful in differentiating SS from MPNST, all too frequently the malignant spindle cell population lacks any distinguishing fine structural features.

With the identification of the nonrandom chromosomal translocation $t(X ; 18)(p 11.2 ; q 11.2)$ in a majority of SSs, it appeared that this translocation could serve as a highly specific discriminator between SS and other soft tissue sarcomas. However, 
past experience has repeatedly demonstrated diminution of specificity with experience in the case of any number of 'specific' markers. This study was therefore initiated to determine the diagnostic specificity of $t(X ; 18)$ by studying a wide variety of benign and malignant spindle cell tumors.

\section{MATERIALS AND METHODS}

All cases studied were retrieved from the files of the Lauren V. Ackerman Laboratory of Surgical Pathology, Washington University Medical Center, St. Louis, MO. In addition to hematoxylin-and-eosinstained sections, each case had at least one paraffin block of tumor from which immunohistochemical and molecular genetic studies could be performed. Electron microscopy was carried out on a selected subset of the tumors as defined below.

Histologic sections from all cases were reviewed independently by the authors in conjunction with a brief history. The final study group consisted of 141 specimens, including 40 SS specimens from 34 patients, 27 MPNST specimens from 20 patients, 16 leiomyomas, 11 leiomyosarcomas, 10 malignant fibrous histiocytomas (MFH), seven congenital infantile fibrosarcomas (CIF), seven hemangiopericytomas, six spindle cell thymomas, four solitary fibrous tumors, four fibrosarcomas (FS), three epithelioid sarcomas (ES), three neurofibromas (NF) and one case each of benign Triton tumor, lowgrade spindle cell sarcoma, and pleomorphic rhabdomyosarcoma.

\section{Immunohistochemistry}

Immunoperoxidase studies were carried out using antibodies to cytokeratins (CK7, CK19, and a pan-CK cocktail of AE1/AE3, CAM5.2, and MAK6), EMA, desmin, smooth muscle actin, CD57 (Leu-7), S-100 protein, collagen IV and CD99 (O13) applied to 3- to $5-\mu \mathrm{m}$ formalin-fixed, paraffin-embedded tissue sections on poly-L-lysine coated slides. Antibody to chromogranin A was applied to all biphasic tumors (Table 1). All primary antibodies were incubated overnight with the tissue sections in moisture chambers at $4^{\circ} \mathrm{C}$. Slides were then developed using a modified avidin-biotin peroxidase complex method as described previously (28) on an automatic stainer. Heat-induced epitope retrieval was carried out for CD57, chromogranin A, CK-AE1/ AE3, CK-CAM5.2, CK-MAK6, CK19, desmin, EMA and $\mathrm{O} 13$ studies. All heat-induced epitope retrieval was completed in a $900 \mathrm{~W}$ microwave oven at $70 \%$ power; citrate heat-induced epitope retrieval was microwaved for $7 \mathrm{~min}$. CK7 cases were treated with pepsin, warmed to $38^{\circ} \mathrm{C}$ with $0.04 \mathrm{~g}$ of pepsin in 10 $\mathrm{mL} \mathrm{H}_{2} \mathrm{O} / 1 \mathrm{~N} \mathrm{HCl}$ solution for $15 \mathrm{~min}$. Sections stained for collagen IV were treated with pronase, warmed to $38^{\circ} \mathrm{C}$ with $0.001 \mathrm{~g}$ of pronase $/ 1 \mathrm{~mL}$ of $\mathrm{PB}$ $\mathrm{pH} 7.6$ solution for $10 \mathrm{~min}$.

Cases were categorized as having a immunostaining profile of classic SS, classic MPNST, or equivocal/other as follows: EMA, CK, and vimentin reactivity, in the absence of staining for CD57, S-100, and collagen IV was considered indicative of SS. Reactivity for S-100, CD57, and collagen IV in the absence of staining for CK and EMA was considered supportive of MPNST. Cases with an immunohistochemical profile that overlapped both patterns were classified as equivocal.

\section{Electron Microscopic Analysis}

Electron microscopy was performed on 13 cases of MPNST, for eight of which fresh tissue fixed in $3 \%$ glutaraldehyde in cacodylate buffer, postfixed in osmium tetroxide, and embedded in epoxy resin, was used. For the five additional cases, archival tissue was dissected from the paraffin block, deparaffinized in xylene, rehydrated, fixed in glutaraldehyde, and postfixed in osmium tetroxide before embedding in epoxy resin. Seven SSs were also examined, all processed from fresh tissue.

In all cases, thick sections stained with toluidine blue were used to select areas for further study. Ultrathin sections, stained with uranyl acetate and

TABLE 1. Immunoperoxidase Stains

\begin{tabular}{|c|c|c|c|c|}
\hline Antibody & Species \& Isotype & Dilution & Pre-Treatment & Manufacturer \\
\hline CD57 & Mouse IgM & $1: 20$ & Citrate hier & Becton-Dickinson, San Jose, CA \\
\hline Chromogranin & Mouse IgG & $1: 20,000$ & None & Boehringer-Mannheim, Indianapolis, IN \\
\hline CK-AE1/AE3 & Mouse IgG & $1: 150$ & Citrate hier & Boehringer-Mannheim \\
\hline CK-CAM 5.2 & Mouse IgG & $1: 150$ & Citrate hier & Becton-Dickinson \\
\hline CK-MAK6 & Mouse IgG & $1: 50$ & Citrate hier & Zymed, South San Francisco, CA \\
\hline CK7 & Mouse IgG & $1: 3,200$ & Pepsin & Dako, Carpinteria, CA \\
\hline CK19 & Mouse IgG & $1: 100$ & Citrate hier & Dako \\
\hline Collagen IV & Mouse IgG & $1: 50$ & Pronase & Dako \\
\hline Desmin & Mouse IgG & $1: 400$ & Citrate hier & Dako \\
\hline EMA & Mouse IgG & $1: 3,000$ & Citrate hier & Dako \\
\hline O13 & Mouse IgG & $1: 200$ & Citrate hier & Signet, Dedham, MA \\
\hline S-100 & Rabbit IgG & $1: 3,000$ & None & Dako \\
\hline SMA & Mouse IgG & $1: 20$ & None & Biogenex, San Ramon, CA \\
\hline
\end{tabular}

Hier, heat-induced antigen retrieval. 
lead citrate, were examined using a Philips CM10 electron microscope. The finding of smooth cell membranes containing maculae-adherences or desmosomes, but without extensive cell processes, were considered characteristic of SS, whereas complex interdigitating cellular processes invested in a basal lamina were considered characteristic of MPNST (25, 29-32).

\section{Molecular Genetic Techniques \\ RNA Extraction}

For all cases, RNA was extracted from formalinfixed, paraffin-embedded tissue. Four $10-\mu \mathrm{m}$ sections of tumor were deparaffinized using xylene and ethanol washes, and digested overnight in buffer (Tris pH 7.5, 20 mm EDTA, 1\% sodium dodecyl sulfate) containing $25 \mathrm{mg}$ proteinase K. Total RNA was then extracted by a modified guanidine isothiocyanate method using Trizol (Gibco/BRL, Gaithersburg, MD) as described (33) and treated with DNAse I before reverse transcription.

\section{Reverse Transcriptase-PCR}

RNA samples were reverse-transcribed using Mulv reverse transcriptase and the Gene Amp RNAPCR kit (Perkin-Elmer, Foster, CA). PCR reactions were carried out using published (33) primers (Table 2) and ampliTaq DNA polymerase, and consisted of a 5 -min $94^{\circ} \mathrm{C}$ hotstart, followed by 35 cycles of annealing at $60^{\circ} \mathrm{C}$ for $1 \mathrm{~min}$., extension at $72^{\circ} \mathrm{C}$ for $30 \mathrm{sec}$., and melting at $94^{\circ} \mathrm{C}$ for $40 \mathrm{sec}$. The PCR products were visualized by ethidium bromide staining after separation by $2 \%$ agarose gel electrophoresis. For each experiment, a cytogenetically confirmed case of biphasic synovial sarcoma (positive control) and a reagent-only water blank (negative control) were assayed along with the tumor specimens. As a control for intact RNA, PCR for the house-keeping gene $\beta 2$-microglobulin (Table 2) was also performed on the cDNA from each case (34). All PCR results (positive and negative) were confirmed by up to four repeat PCR analyses; for each repeat analysis, new RNA was prepared from four additional sections of tumor, followed by re-

TABLE 2. Primers and Probe

\begin{tabular}{|c|c|}
\hline $\begin{array}{c}\text { Primer } \\
\text { Designation }\end{array}$ & Sequence \\
\hline $\begin{array}{l}\beta 2 \text {-microglobulin } \\
\text { forward }\end{array}$ & $5^{\prime}-\mathrm{ACCCCCACTGAAAAAGATGA}-3^{\prime}$ \\
\hline $\begin{array}{l}\beta 2 \text {-microglobulin } \\
\text { reverse }\end{array}$ & 5'-ATCTTCAAACCTCCATGATG-3' \\
\hline SSA forward & 5'-AGACCAACACAGCCTGGACCAC-3' \\
\hline SSX reverse & 5'-тССтCTGCTGGCTTCTTG-3'a \\
\hline SYT-SSX probe & 5'-GAATATGACCAGATCATCATGCCCAAG-3' \\
\hline
\end{tabular}

verse transcription, and PCR amplification as outlined for the initial evaluation.

\section{DNA Sequencing}

Cases sequenced included a subset of SSs and all other cases in which reverse transcriptasepolymerase chain reaction (RT-PCR) for $\mathrm{t}(\mathrm{X} ; 18)$ produced a dominant band of the expected size by ethidium bromide staining. Briefly, the PCR product was cloned into vector pCR2.1 using the TA cloning kit (Invitrogen, Carlsbad, CA) and then sequenced using the Taq dideoxy terminator cycle sequencing kit (Applied Biosystems Inc., Foster City, CA) and a fluorescent DNA sequencer (Model 373A; Applied Biosystems Inc.). DNA sequence analysis was facilitated by BLAST sequence similarity searches using the National Center for Biotechnology Information database (http://www.ncbi. nlm.nih.gov/BLAST/).

\section{Southern Blot Hybridization}

For selected cases, the PCR products were transferred to a nylon membrane and hybridized with a ${ }^{32} \mathrm{P}$-radiolabeled oligonucleotide probe specific for the SYT-SSX fusion junction (Table 2) as described (33).

\section{RESULTS}

\section{Immunohistochemistry}

Among the synovial sarcomas studied, 65\% showed reactivity for pan-CK, $48 \%$ for CK7, and $36 \%$ for CK19. EMA was reactive in $94 \%$ of the cases, CD99 (O13) in 85\%, CD57 in $72 \%$, and S-100 in $22 \%$ (Table 3).

Among the peripheral nerve sheath tumors (PNSTs) evaluated, which included 20 MPNSTs and three neurofibromas, only $1 \%$ showed reactivity for pan-cytokeratin, $18 \%$ for CK7, and none for CK19. [These results are very much in line with recent observations (35) that staining with keratin subtypes can be of value in the differentiation of MPNSTs from SSs.] Reactivity for the classic 'neural' markers CD57 and S-100 protein was observed in $55 \%$ and $62 \%$ of cases respectively, whereas $64 \%$ stained for collagen IV. Eighty-six percent of MPNSTs stained for CD99.

Three of the 11 biphasic synovial sarcomas (27\%) showed epithelial cell reactivity for chromogranin A, while no reactivity was noted in any of the seven MPNSTs evaluated, contrary to the findings reported by others (36).

\section{Molecular Analysis}

Twenty-nine of 34 cases of SS $(85 \%)$ contained the translocation $t(X ; 18)$, which is consistent with 
TABLE 3. Immunoperoxidase Results

\begin{tabular}{lcccccccccc}
\hline & Pan-CK & CK7 & CK19 & EMA & Desmin & SMA & CD57 & S-100 & Coll IV & CD99 \\
\hline SS & $22 / 34$ & $16 / 33$ & $12 / 33$ & $31 / 33$ & $6 / 31$ & $3 / 30$ & $23 / 32$ & $7 / 32$ \\
PNST & $2 / 17$ & $4 / 17$ & $0 / 17$ & $3 / 17$ & $7 / 17$ & $1 / 17$ & $11 / 17$ & $8 / 16$ & $11 / 17$ & $14 / 17$ \\
MPNST & $0 / 5$ & $0 / 5$ & $0 / 5$ & $2 / 5$ & $2 / 5$ & $2 / 5$ & $1 / 5$ & $5 / 5$ & $3 / 5$ & $5 / 5$ \\
\hline
\end{tabular}

Data expressed as number of positive cases over total cases studied.

PNST, peripheral nerve sheath tumors with $\mathrm{t}(\mathrm{X} ; 18)$ including 15 MPNSTs and two neurofibromas; MPNST, malignant peripheral nerve sheath tumors without $\mathrm{t}(\mathrm{X} ; 18)$.

published results (37) (Table 4). Eleven of the cases were biphasic, and the remaining 23 were monophasic spindle cell tumors. In four cases, tissue from metachronous biopsy or excision procedures was available, and in all four, analysis of the additional material yielded concordant results.

Fifteen of 20 MPNSTs (75\%) also had the translocation $\mathrm{t}(\mathrm{X} ; 18)$ (Figure 1). The MPNSTs included in the study could be divided into three groups: a group of malignant Triton tumors; a group of tumors either arising inpatients with documented NF-1 and/or in direct association with a peripheral nerve; and a group of tumors arising inpatients without NF-1 and unassociated with peripheral nerve but having combined histological, immunohistochemical and fine structural features of MPNST. Additional tissue was available from follow-up surgical procedures in five cases, all from the site of the primary tumor. For four of these cases, analysis of the additional tissue yielded results concordant with those obtained from the original tumor tissue; three consistently harbored $\mathrm{t}(\mathrm{X}$; 18 ), whereas one consistently lacked it. For one case shown to have $t(X ; 18)$ in the original tissue, only two of three subsequent tumor excision specimens contained the $\mathrm{t}(\mathrm{X} ; 18)$.

The presence of a correctly-sized or absence of an RT-PCR product as visualized by ethidium bromide staining correlated with the presence (or absence) of a single band by Southern blot hybridization (Figure 2 and data not shown) using a probe

TABLE 4. Results of $t(X ; 18)$ Analysis by Tumor Type $(n=128)$

\begin{tabular}{lcc}
\hline & $\begin{array}{c}\text { Number of } \\
\text { cases }\end{array}$ & $\begin{array}{c}\text { Number with } \\
\mathrm{t}(\mathrm{X} ; 18)\end{array}$ \\
\hline Synovial sarcoma & 34 & $29(85 \%)$ \\
Malignant peripheral nerve sheath tumor & 20 & $15(75 \%)$ \\
Fibrosarcoma (adult) & 4 & $1(25 \%)$ \\
Malignant fibrous histiocytoma & 10 & $1(10 \%)$ \\
Fibrosarcoma (congenital-infantile) & 7 & $1(14 \%)$ \\
Leiomyoma & 16 & 0 \\
Leiomyosarcoma & 11 & 0 \\
Hemangiopericytoma & 7 & 0 \\
Spindle cell thymoma & 6 & 0 \\
Solitary fibrous tumor & 4 & 0 \\
Epithelioid sarcoma & 3 & 0 \\
Neurofibroma & 3 & $2^{a}(67 \%)$ \\
Others & 3 & 0 \\
\hline
\end{tabular}

$a$ The two positive neurofibromas were a cellular neurofibroma and an atypical neurofibroma; see text for details.

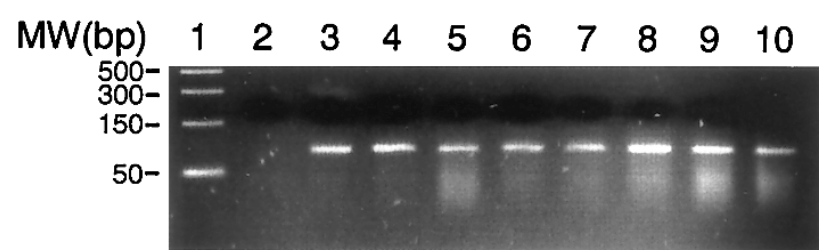

FIGURE 1. Reverse transcriptase-polymerase chain reaction (RT-PCR) demonstration of $t(X ; 18)$ in malignant peripheral nerve sheath tumors (MPNSTs) and fibrosarcoma (FS) as well as synovial sarcoma (SS). Lane 1, PCR molecular mass markers; lane 2, negative control water blank; lane 3, positive control SS, cytogenetically proven to have $t(X ; 18)$; lane 4, biphasic SS; lane 5, case 12 (rectovaginal septal MPNST in 60-yearold woman without neurofibromatosis (NF-1); see Figure 4); lane 6, case 6 (left proximal thigh MPNST in 16-year-old girl with NF-1); lane 7, case 4 (paraspinal MPNST in 13-year-old girl with NF-1); lane 8, case 15 (MTT of sciatic nerve in 44-year-old man without NF-1); lane 9, case 1 (MTT of anterior abdominal wall in 24-year-old woman with NF-1see Figure 2); lane 10, case 22 (upper arm FS in 50-year-old woman). Case numbers refer to Table 5 .

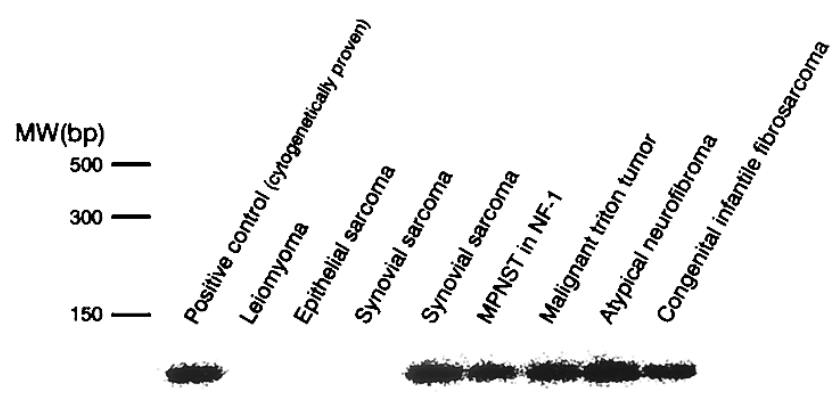

50

$\begin{array}{llllllllll}1 & 2 & 3 & 4 & 5 & 6 & 7 & 8 & 9 & 10\end{array}$

FIGURE 2. Southern blot hybridization of the reverse transcriptasepolymerase chain reaction (RT-PCR) product from selected cases using a probe specific for the $S Y T$-SSX fusion junction of $t(X ; 18)$. Lane 2 is the positive control synovial sarcoma (SS) cytogenetically proven to harbor $\mathrm{t}(\mathrm{X} ; 18)$. Lanes 3 through 5 showed no evidence of the appropriatelysized PCR product by ethidium bromide staining, whereas lanes 6 through 10 (lane 7, case 2; lane 8, case 15; lane 9, case 16; and lane 10, case 24) all showed the appropriately-sized PCR product by routine ethidium bromide staining. Case numbers refer to Table 5 .

specific for the SYT-SSX fusion junction (Table 2). Furthermore, DNA sequence analysis of a subset of SSs, as well as all other cases in which RT-PCR for $t(X ; 18)$ produced a dominant band of the expected size, showed that the PCR product had $100 \%$ homology with the corresponding region of fusion between SYT and SSX in $\mathrm{t}(\mathrm{X} ; 18)$ (Figure 3 and data not shown).

The 15 MPNST cases (Table 5) bearing the translocation $\mathrm{t}(\mathrm{X} ; 18)$ included three malignant Triton tu- 

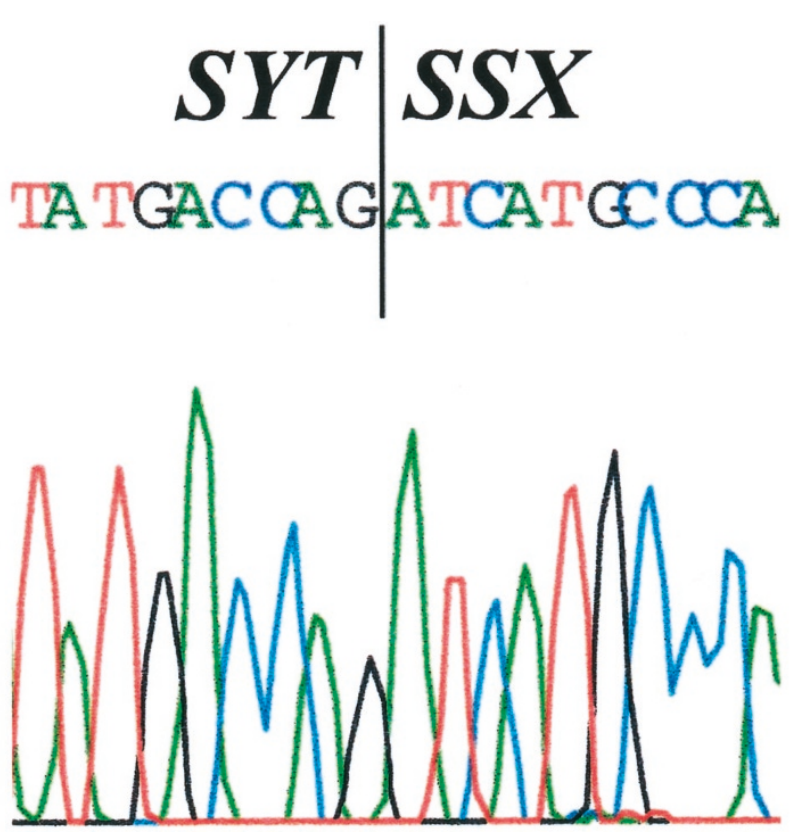

FIGURE 3. Representative DNA sequence of the reverse transcriptase-polymerase chain reaction (RT-PCR) product from a malignant peripheral nerve sheath tumor (MPNST) (case 2 of Table 5). Lower region, chromatogram produced by the automated fluorescent DNA sequencer; upper region, DNA sequence showing $100 \%$ homology to the sequence of the fusion junction between SYT and SSX (indicated by the vertical line) in $\mathrm{t}(\mathrm{X} ; 18)$.

mors, one of which (case 1) arose in the anterior abdominal wall of a patient with neurofibromatosis (Figure 4), and two that arose in the soft tissue around the hip and within the sciatic nerve, respectively, inpatients without NF-1 (cases 14 and 15). One MPNST (case 2) arose in a preexisting neurofibroma of the brachial plexus in an NF-1 patient (Figure 5), and four others (cases 3 to 6) arose inpatients with NF-1. In cases 1,3 , and 4 , material available from sequential biopsies was also evaluated and in each case the additional tumor samples also harbored $t(X ; 18)$. In case 1 , fresh tissue constituted one of the additional specimens tested.

Seven cases (cases 7 to 13) were MPNSTs from patients without a history of NF-1, where the diagnosis was based upon the combined histomorphology, immunophenotype and fine structural analysis. In case 12, an MPNST arising in the rectovaginal septum of a 60 -year-old woman, there were definitive electron microscopic features of nerve sheath differentiation (Figure 6). In addition to the MPNSTs, one atypical neurofibroma and one cellular neurofibroma (cases 16 and 17) also had the translocation $\mathrm{t}(\mathrm{X} ; 18)$ (Figures 7 and 8). Neither patient had clinical features of NF-1.

Apart from SSs and MPNSTs, one of four fibrosarcomas, one of seven CIFs, and one of 10 MFHs were also shown to bear the translocation $t(X ; 18)$. The diagnoses in these cases were based on morphology, and an immunophenotype showing vimentin-only positivity for the FS and the MFH, with coexpression of CD99 in the CIF. Clinical follow-up was not available for the patients with the MFH or FS that contained $t(X ; 18)$; however, the CIF harboring $t(X ; 18)$, which admittedly arose in an unusual location on the scalp, behaved as expected with partial regression after initial biopsy, and total regression after partial resection.

\section{Electron Microscopy}

Electron microscopic (EM) examination demonstrated definitive nerve sheath features in six of the cases of MPNST investigated, all of which had RTPCR and sequence-based proof of $t(X ; 18)$. In each of these, fresh tissue was used for EM evaluation. A further seven cases of MPNST had indeterminate fine structural features on EM examination, mainly because poor preservation (for five of these latter cases, tissue was retrieved from paraffin blocks); five of these seven cases had $t(X ; 18)$ proven by RT-PCR and sequence analysis. Of the seven cases of SS evaluated by EM, six had fine structural features of SS and one was indeterminate; $t(X ; 18)$ was demonstrated in six of these cases, including the case with indeterminate ultrastructural findings.

Table 5 is a summary of the clinical details, immunohistochemical, electron microscopic, and molecular findings for all MPNSTs, and for the cellular and atypical neurofibromas, MFH, FS, and CIF harboring $\mathrm{t}(\mathrm{X} ; 18)$.

\section{DISCUSSION}

Cytogenetic studies identified the characteristic translocation $\mathrm{t}(\mathrm{X} ; 18)(\mathrm{p} 11.2 ; \mathrm{q} 11.2)$ that is present in approximately $90 \%$ of SSs, of both mono- and biphasic types (38-45). These studies led, in parallel, to the view that $\mathrm{t}(\mathrm{X} ; 18)$ is specific for synovial sarcoma, a view has been supported by the few molecular studies evaluating other spindle cell tumors for the translocation $(37,46-49)$. Nonetheless, Balazs et al. (47) and Hiraga et al. (37) did, in fact, demonstrate $\mathrm{t}(\mathrm{X} ; 18)$ in MPNSTs, and van de Rijn et al. (49) detected $t(X ; 18)$ in a case with features of both SS and MPNST, but these investigators subsequently rediagnosed the positive cases as SSs. We hypothesized that this apparent bias of reclassification of tumors as SS based upon observation of $\mathrm{t}(\mathrm{X} ; 18)$ has simultaneously been driven by, and perpetuated, the belief that $t(X ; 18)$ is specific for SS. Our study was designed to investigate whether spindle cell neoplasms other than SS can contain $t(X ; 18)$ and was designed to focus primarily but not exclusively on MPNST, because SS and MPNST have such well recognized histological, ultrastructural, and immunophenotypic similarities.

Our cases were evaluated and classified on the basis of standard morphologic and immunohistochem- 
TABLE 5. Clinicopathologic and Molecular Correlations

\begin{tabular}{|c|c|c|c|c|c|c|c|}
\hline Case & Age/Sex & Site & NF-1 & Histology & Immunopositivity & EM & $\mathrm{t}(\mathrm{X} ; 18)$ \\
\hline 1 & $24 \mathrm{~F}$ & Abdominal wall & $\mathrm{Y}$ & MTT & CD99, Desmin & Indeterminate & $\mathrm{Y}$ \\
\hline 2 & $33 \mathrm{M}$ & Brachial plexus & $\mathrm{Y}$ & MPNST & Neural & Not done & $\mathrm{Y}$ \\
\hline 3 & $17 \mathrm{~F}$ & Gluteal region & $\mathrm{Y}$ & MPNST & Neural & Indeterminate & $\mathrm{Y}$ \\
\hline 4 & $13 \mathrm{~F}$ & Paraspinal & $\mathrm{Y}$ & MPNST & Equivocal & Not done & $\mathrm{Y}$ \\
\hline 5 & $17 \mathrm{M}$ & Retroperitoneum & $\mathrm{Y}$ & MPNST & Neural & Not done & $\mathrm{Y}$ \\
\hline 6 & $16 \mathrm{~F}$ & Thigh & $\mathrm{Y}$ & MPNST & Neural & Indeterminate $^{a}$ & $\mathrm{Y}$ \\
\hline 7 & $81 \mathrm{M}$ & Thigh & $\mathrm{N}$ & MPNST & Neural & Indeterminate & $\mathrm{Y}$ \\
\hline 8 & $34 \mathrm{M}$ & Chest wall & $\mathrm{N}$ & MPNST & Neural & Indeterminate $^{a}$ & $\mathrm{Y}$ \\
\hline 9 & $52 \mathrm{M}$ & Chest wall & $\mathrm{N}$ & MPNST & Neural & Not done & $\mathrm{Y}$ \\
\hline 10 & $48 \mathrm{~F}$ & Buttock & $\mathrm{N}$ & MPNST & Neural & Nerve sheath ${ }^{a}$ & $\mathrm{Y}$ \\
\hline 11 & $49 \mathrm{M}$ & Forearm & $\mathrm{N}$ & MPNST & Neural & Nerve sheath ${ }^{a}$ & $\mathrm{Y}$ \\
\hline 12 & $60 \mathrm{~F}$ & Rectovaginal & $\mathrm{N}$ & MPNST & Equivocal & Nerve sheath ${ }^{a}$ & $\mathrm{Y}$ \\
\hline 13 & $54 \mathrm{~F}$ & Dorsal root $\mathrm{S} 1$ & $\mathrm{~N}$ & MPNST & Neural & Nerve sheath ${ }^{a}$ & $\mathrm{Y}$ \\
\hline 14 & $83 \mathrm{M}$ & Hip & $\mathrm{N}$ & MTT & CD57, SMA, Desmin & Nerve sheath ${ }^{a}$ & $\mathrm{Y}$ \\
\hline 15 & $44 \mathrm{M}$ & Sciatic nerve & $\mathrm{N}$ & MTT & CD57, CD99, DES, CK, EMA & NS W/ Diverg Diff ${ }^{a}$ & $\mathrm{Y}$ \\
\hline 16 & $28 \mathrm{M}$ & Mediastinum & $\mathrm{N}$ & NF, atypical & Neural & Not done & $\mathrm{Y}$ \\
\hline 17 & $10 \mathrm{M}$ & Scalp & $\mathrm{N}$ & NF, cellular & Neural & Not done & $\mathrm{Y}$ \\
\hline 18 & $9 \mathrm{M}$ & Foot & $\mathrm{N}$ & MPNST & Neural & Not done & $\mathrm{N}$ \\
\hline 19 & $83 \mathrm{~F}$ & Paranasal sinuses & $\mathrm{N}$ & MTT & CD99, CD57, S-100, Desmin & Indeterminate & $\mathrm{N}$ \\
\hline 20 & $3 \mathrm{M}$ & Forearm & $\mathrm{N}$ & MTT & CD99, S-100, Desmin & Indeterminate & $\mathrm{N}$ \\
\hline 21 & $42 \mathrm{~F}$ & Axilla & $\mathrm{Y}$ & MPNST & Neural & Not done & $\mathrm{N}$ \\
\hline 22 & $58 \mathrm{~F}$ & Paranasal sinuses & $\mathrm{N}$ & MPNST & Neural & Not done & $\mathrm{N}$ \\
\hline 23 & $50 \mathrm{~F}$ & Arm & $\mathrm{N}$ & FS & Focal CD57 & Not done & $\mathrm{Y}$ \\
\hline 24 & $3 / 12 \mathrm{M}$ & Scalp & $\mathrm{N}$ & CIF & Vimentin only & Not done & $\mathrm{Y}$ \\
\hline 25 & $74 \mathrm{M}$ & Hip & $\mathrm{N}$ & MFH & Vimentin only & Not done & $\mathrm{Y}$ \\
\hline
\end{tabular}

${ }^{a}$ Fresh tissue used for EM evaluation.

NF-1, neurofibromatosis-1; Y, yes; N, no; NF, neurofibroma; MTT, malignant triton tumor; MPNST, malignant peripheral nerve sheath tumor; Translocation t(X;18): Y, present by RT-PCR and confirmed by sequence; N, absent. Neural, immunophenotype consistent with nerve sheath origin (S-100, CD57, COL IV reactivity present). Nerve sheath, fine structural features of nerve sheath (see Materials and Methods). NS W/ Diverg Diff, nerve sheath with divergent differentiation (i.e., MTT). FS, fibrosarcoma; CIF, congenital infantile fibrosarcoma; MFH, malignant fibrous histiocytoma.

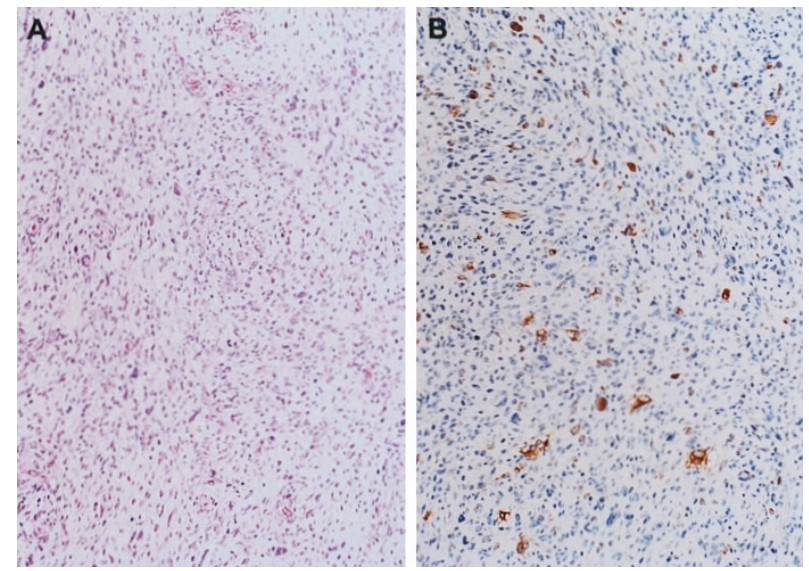

FIGURE 4. Case 1: malignant triton tumor. A, spindle cell sarcoma with interspersed rhabdomyoblasts (hematoxylin and eosin). B, rhabdomyoblasts are highlighted by a desmin immunostain.

ical methods without knowledge of the RT-PCR results. Each tumor was thoroughly characterized histologically, ultrastructurally (when available), and immunohistochemically. In accordance with other studies, we found that $85 \%$ of the SSs had the $\mathrm{t}(\mathrm{X}$; 18)(p11.2; q11.2) translocation. However, $75 \%$ of the MPNSTs also harbored the same translocation. In addition, one of four fibrosarcomas, one of seven congenital-infantile fibrosarcomas, and one of 10 MFHs also contained the translocation, as did two neurofibromas.

Given that the exclusivity of $t(X ; 18)$ to SS is challenged by the results of this study, two fundamental questions pertaining to our methodology require consideration. One relates to technical aspects of our analysis, and the other to the diagnostic determinants employed, particularly for the diagnosis of MPNST versus SS, as this was the non-SS tumor type most consistently associated with the $t(X ; 18)$.

It is unlikely that technical factors account for the findings in this study. First, we used PCR primers that have been used by others in previously published studies of formalin-fixed, paraffin-embedded tissue. Southern blot hybridization using a probe specific for the SYT-SSX fusion junction of $\mathrm{t}(\mathrm{X} ; 18)$ showed binding to the appropriately sized RT-PCR product (Figure 2), and the identity of the PCR product was further confirmed by DNA sequence analysis (Figure 3). Second, to minimize the likelihood of cross-contamination, our protocol employed a single round of PCR rather than a set of nested PCRs. Third, the water-only negative controls included in each PCR reaction did not detect any evidence of contamination. Fourth, all non-SS cases were subjected to repeat analysis beginning with extraction of RNA from freshly cut sections from the tissue blocks. All non-SSs demonstrating $\mathrm{t}(\mathrm{X} ; 18)(\mathrm{p} 11.2 ; \mathrm{q} 11.2)$ were reanalyzed at least twice, always with the same result; all non-SSs with an initially negative result were also reanalyzed, again with confirmation of the original result in all cases. Similarly, analysis of a subset of SSs, whether positive or negative, was repeated and confirmed the original result. As delineated in the Results, addi- 

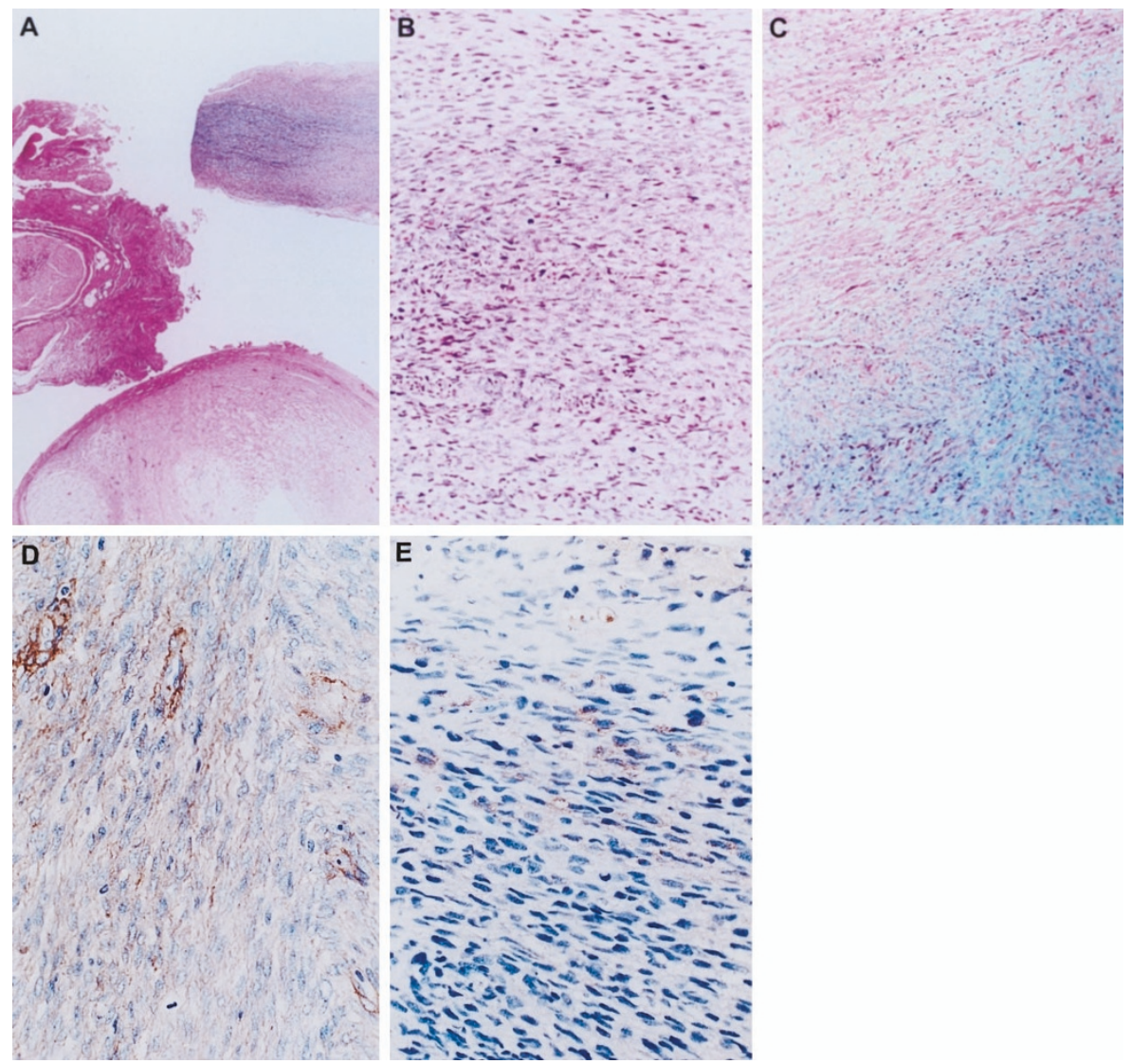

FIGURE 5. Case 2: Malignant peripheral nerve sheath tumor (MPNST) arising in a preexisting neurofibroma of the brachial plexus. A, low-power view shows normal nerve, neurofibroma, and MPNST components (hematoxylin and eosin). B, high-power view of MPNST shows cellular, mitotically active spindle cell sarcoma; C, junction of neurofibroma with MPNST. D, focal cytoplasmic CD57 immunoreactivity; E, diffuse membrane-associated collagen IV immunoreactivity.
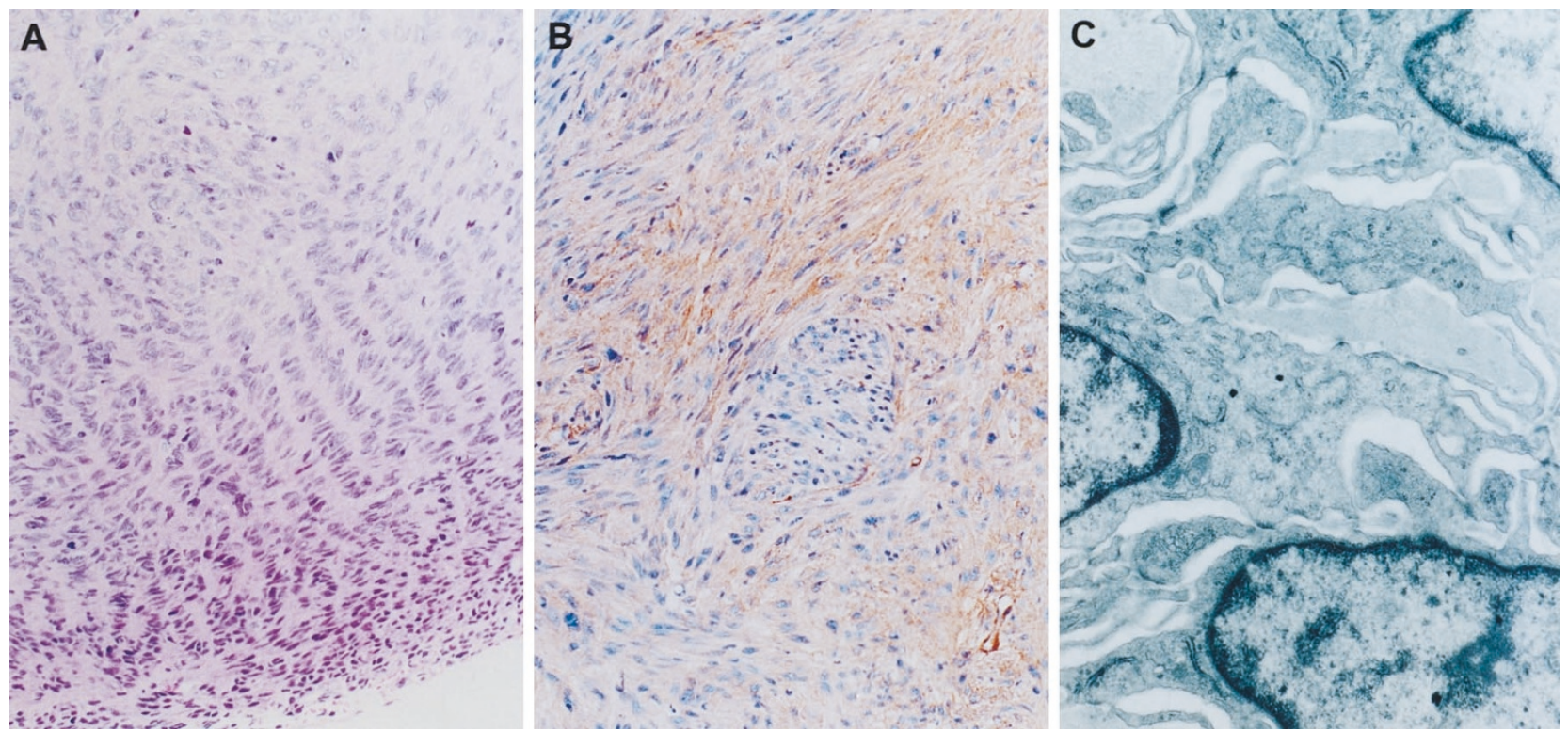

FIGURE 6. Case 12: Rectovaginal malignant peripheral nerve sheath tumor (MPNST). A, spindle cell sarcoma with nuclear palisading (hematoxylin and eosin). B, diffuse membrane-associated collagen IV immunoreactivity. C, electron micrograph shows complex interdigitating membrane processes.

tional tissue samples obtained from subsequent surgical procedures yielded concordant findings by RT-PCR testing. Fifth, the detection of $t(X ; 18)$ in tumors other than SS was clustered primarily in cases of MPNST, rather than randomly in the other tumor types, as might be expected if technical er- 


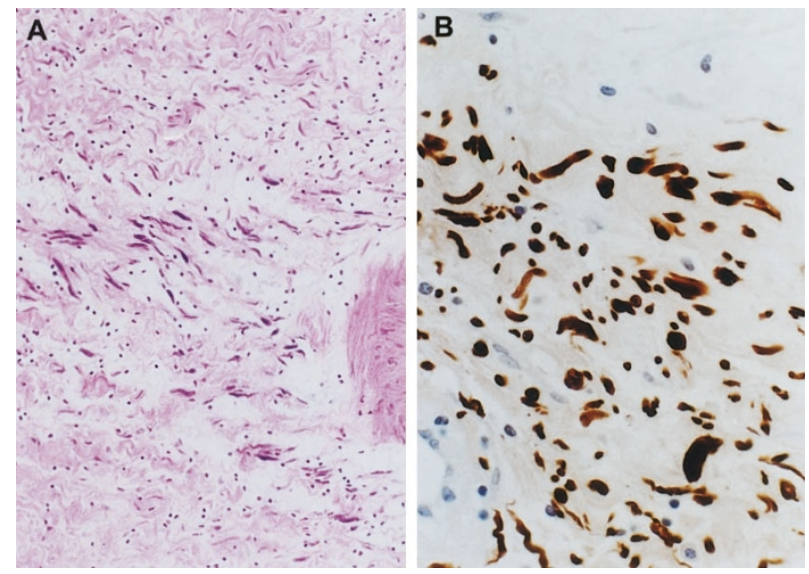

FIGURE 7. Case 16: A, atypical neurofibroma shows nuclear pleomorphism (hematoxylin and eosin). B, S-100 immunostain shows nuclear reactivity.

rors were responsible for the results. Although individual cases of fibrosarcoma, congenital-infantile fibrosarcoma, and MFH harbored the translocation, $t(X ; 18)$ was not found in more than 40 additional cases of benign and malignant spindle cell lesions.

Similarly, the results of this study can not be explained by diagnostic inaccuracies; diagnoses were based on well-established morphologic, immunohistochemical, and EM criteria, and were carefully scrutinized, because SS, especially the monophasic variant, and MPNST have such substantial morphologic and immunophenotypic overlap. As shown in Table 5, 15 patients had $t(X ; 18)$ translocation-positive malignant tumors of nerve. Six MPNSTs occurred in persons with neurofibromatosis, including an MPNST (case 2) that arose within a neurofibroma of the brachial plexus. In addition to their origin in the clinicopathologic setting of NF-1, each of these six neoplasms had histologic and immunophenotypic features consistent with MPNST. Three other translocation-positive tumors were malignant Triton tumors; one arose in a patient with NF-1 (case 1), one arose within the sciatic nerve (case 15), and two had EM features of nerve sheath differentiation (cases 14 and 15).

Our series also included MPNSTs occurring as sporadic, nonsyndromic neoplasms. Seven of these tumors (cases 7 to 13) were malignant spindle cell neoplasms with histologic features consistent with nerve sheath differentiation. Apart from case 13 (which arose in the S1 dorsal root), these tumors did not arise in association with a nerve. However, all seven showed immunohistochemical and/or ultrastructural evidence of nerve sheath differentiation in accordance with the criteria for MPNST outlined by Woodruff (50).

Two other tumors (cases 16 and 17) are also noteworthy. Both were solitary neurofibromas which harbored $t(X ; 18)$, and each arose in a patient without clinical evidence of NF-1. Allowing the presence of $t(X ; 18)$ alone to serve as the superseding criterion for a diagnosis of SS in these two cases would not only have resulted in an incorrect diagnosis but also would have erroneously categorized these two benign lesions as malignant.

Only a limited number of prior studies have identified $t(X ; 18)$ in tumors other than SS by molecular methods similar to those we used $(37,47)$. However, in these studies, the authors chose to explain their results by reclassifying MPNSTs harboring $t(X ; 18)$ as SSs $(37,47,49)$. For example, in the series reported in abstract form by Balazs (47), four of nine MPNSTs evaluated bore $t(X ; 18)$, two of which extensively involved nerves and two of which expressed S-100 protein; however, a later publication (49) indicates that all four tumors were most likely synovial sarcomas involving nerve (although the reasons for this reclassification are not discussed).

Other groups have reported a virtually perfect correlation between the presence of $t(X ; 18)$ and the diagnosis of SS $(26,33,46,48)$. However, in two of these studies $(26,33)$ examining the specificity of $t(X ; 18)$ for SS, the authors state that cases with ambiguous morphologic, immunophenotypic, and/or ultrastructural features were classified as SS, apparently based solely on the demonstration of $\mathrm{t}(\mathrm{X} ; 18)$ by molecular genetic testing. Hiraga et al. (37) reported demonstration of $\mathrm{t}(\mathrm{X} ; 18)$ in three unclassified sarcomas and one of 11 MPNSTs, but because the latter tumor was not associated with a large nerve and was composed of fascicles of "monotonous symmetrical spindled cells" that were nonreactive for S-100 protein, it was reclassified as SS. None of 12 MPNSTs studied by van de Rijn et al. (49) contained $t(X ; 18)$, although one additional lesion that had light and electron microscopic features of MPNST and showed immunoreactivity for S-100 protein as well as EMA was re-classified as SS on the basis of the presumed specificity of the $S Y T$ SSX fusion product it contained.

In many studies, therefore, demonstration of $t(X$; 18) has been the criterion standard for diagnosis; morphologic diagnostic criteria were superseded by a molecular finding interpreted with a bias that $\mathrm{t}(\mathrm{X} ; 18)$ is specific for SS. Nonetheless, as a recent case report illustrates (51), other authors remain less certain of the diagnostic significance of $t(X ; 18)$ in cases that have some histological features of MPNST. Our results also challenge the concept that $t(X ; 18)$ is a specific tumor marker and suggest that classification of a neoplasm as SS based solely on the result of molecular genetic testing is inappropriate. In this context, it is noteworthy that none of the prior studies specifically included MTTs or cases of MPNST arising inpatients who have NF-1.

With increasing application of molecular genetics, exceptions to the common perception that a particular cytogenetic or molecular event is entirely 


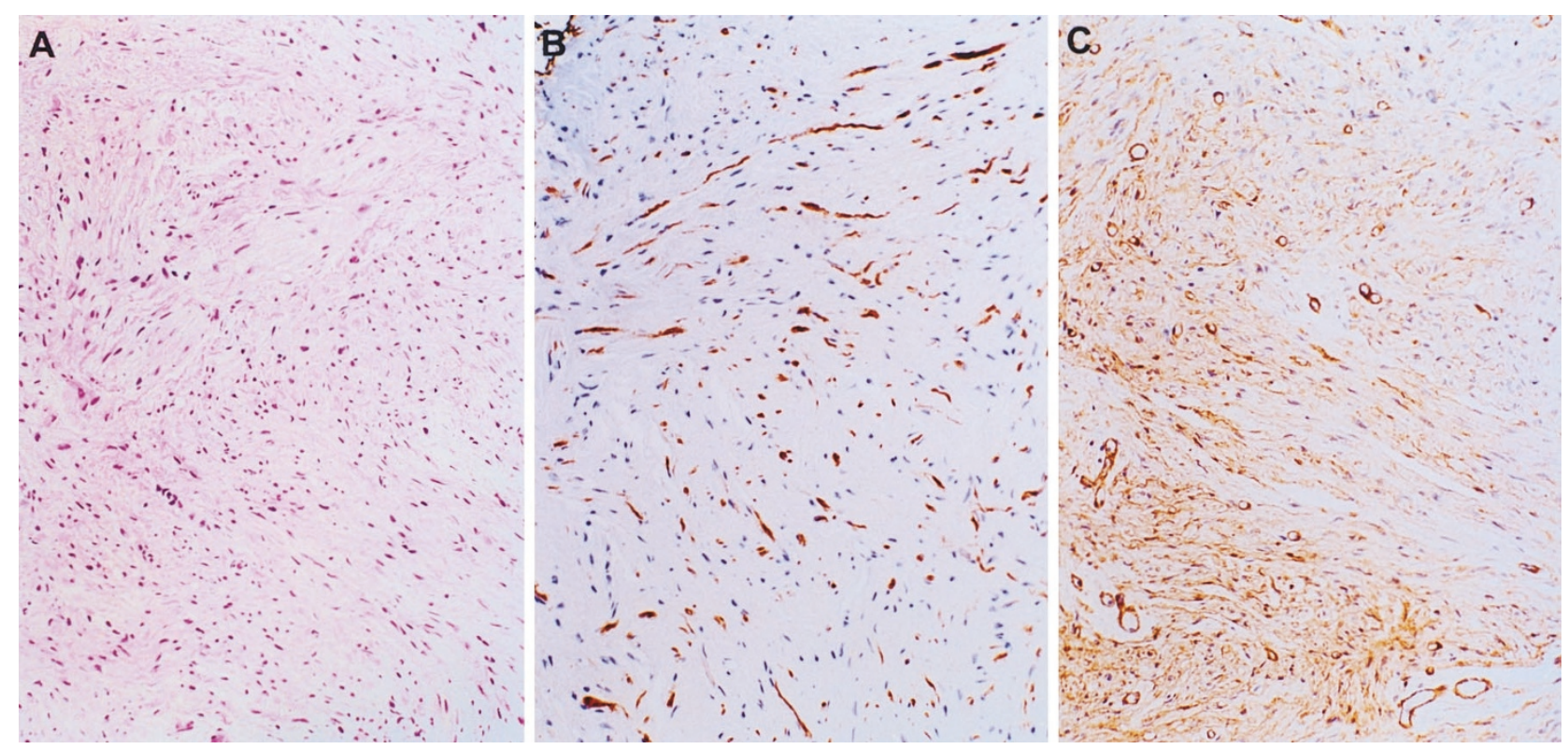

FIGURE 8. Case 17: A, cellular neurofibroma (hematoxylin and eosin). B, S-100 immunostain shows nuclear reactivity. C, diffuse membraneassociated collagen IV immunoreactivity.

tumor specific have already emerged. For example, an intraabdominal desmoplastic small round-cell tumor (DSRCT), two classic neuroblastomas, and two examples of mixed embryonal and alveolar rhabdomyosarcoma (ARMS) have all been shown to harbor translocations typical of Ewing sarcomaprimitive neuroectodermal tumor (EWS-PNET) rather than the translocations characteristically associated with DSRCT and alveolar rhabdomyosarcoma (52-54). These cases are emblematic of the dilemma presented by the results of our study. Should we simply ignore the morphologic and immunophenotypic features of MPNST in the cases of the present study with $t(X ; 18)$ and consider these tumors SSs? Similarly, should a DSRCT with an EWS-ERG fusion transcript be considered an EWSPNET, or a mixed embryonal-alveolar rhabdomyosarcoma be diagnosed as EWS-PNET with aberrant rhabdomyoblastic differentiation?

The translocation $(\mathrm{X} ; 18)$ has apparently escaped detection in most, but not all (51), of the limited number of MPNST karyotypes reported to date, which have shown an inconsistent and remarkably complex array of cytogenetic abnormalities (55-59). Discrepancies between the results of standard cytogenetic analysis and RT-PCR have, however, been demonstrated for $\mathrm{t}(\mathrm{X} ; 18)$. Sorensen and Triche reported a case of SS in which RT-PCR and fluorescent in situ hybridization detected $\mathrm{t}(\mathrm{X} ; 18)$ that was not identified by cytogenetics (60). A so-called masked translocation was found in another case of SS (61) in which a second reverse translocation obscured the $t(X ; 18)$ on karyotypic analysis, yet another example of RT-PCR or fluorescent in situ hybridization as more sensitive methods for detecting a translocation than standard metaphase cytogenetics. In more general terms, the period of in vitro cell culture preceding cytogenetic analysis may favor tumor cell clones harboring specific chromosomal abnormalities, resulting in a karyotype that reflects an in vitro growth advantage rather than a genetic abnormality representative of the major clone in vivo. We cannot easily explain why molecular studies have not identified $t(X ; 18)$ in more cases of MPNST to date, but our results are not unique $(37,47,51)$.

Although $\mathrm{t}(\mathrm{X} ; 18)$ has been demonstrated in the spindled as well as the epithelial components of SS (62), it is possible that, in the setting of MPNST, the translocation is an epiphenomenon that merely reflects chromosomal instability and is therefore unrelated to the genetic events responsible for malignant transformation. As noted previously, the reported karyotypes of MPNST are quite complex and the presence of $t(X ; 18)$ may simply represent one of multiple accumulated genetic abnormalities. If $\mathrm{t}(\mathrm{X} ; 18)$ is directly involved in the genesis of MPNST and SS, then a genetic linkage may well exist between these two entities, offering an explanation for the recognized morphologic similarities between them. Recent reports of $t(X ; 18)$ in a case of "biphasic synovial sarcoma with morphological features of neural differentiation" [in which the cultured tumor cells had a striking neural immunophenotype (63)] and $t(X ; 18)$ in a case which by ultrastructural analysis had features of both synovial sarcoma and nerve sheath differentiation (49), are particularly interesting in light of such a hypothesis. 
Three further cases in this study, one each of FS, $\mathrm{MFH}$, and CIF, harbored $\mathrm{t}(\mathrm{X} ; 18)$. Given the light microscopic and immunohistochemical characteristics of these tumors, we believe that all three cases were correctly diagnosed. Cytogenetic studies have, in fact, previously reported $t(X ; 18)$ in one MFH (41) and one FS (64). It is possible to argue that these cases, as poorly differentiated spindled cell tumors, fall within the broad categories of MPNST or SS and that they therefore offer support for the specificity of $t(X ; 18)$ in a broader category of SS-MPNST. However, we interpret these cases as additional proof of the nonspecificity of $t(X ; 18)$ for SS and as evidence that $t(X ; 18)$ can be demonstrated in a variety of tumors in addition to MPNST.

Even before the list of soft tissue sarcomas with primary or apparent "tumor-specific" translocations had reached its current length, some had voiced the opinion that cytogenetics is a promising tool with which to characterize cells and lineages independent of their structural and functional phenotypes (65). At least in regard to the $t(X ; 18)$ translocation, however, the results of the present study imply that it is premature to abandon the morphologic aspects of pathologic diagnosis. In general terms, our results are reminiscent of past experience with immunohistochemistry in that certain antibodies were initially promoted as specific for a particular tumor type, but over time, and with additional studies, were shown to lack specificity equivalent to their degree of sensitivity.

\section{REFERENCES}

1. Haagensen CD, Stout AP. Synovial sarcoma. Annu Surg 1944; 120:826-42.

2. Pack GT, Ariel IM. Synovial sarcoma (malignant synovioma). A report of sixty cases. Surgery 1950;28:1047-1084.

3. Hampole MK, Jackson BA. Analysis of 25 cases of malignant synovioma. Can Med Assoc J 1968;99:1025-9.

4. Coley BL, Pierson JC Synovioma. Report of fifteen cases with review of the literature. Surgery 1936;1:113-124.

5. DeSanto DA, Tennant R, Rosahn PD. Synovial sarcomas in joints, bursae and tendon sheaths. A clinical and pathological study of sixteen cases. Surg Gynecol Obstet 1941;72:95181.

6. Loehr E. Zur klinischen Diagnostik der malignen Synovialome. Zentralbl Chir 1967;42:2697-701.

7. Batsakis JG, Nishiyama RH, Sullinger GD. Synovial sarcomas of the neck. Arch Otolaryngol Head Neck Surg 1967;85:32731.

8. Roth JA, Enzinger FM, Tannenbaum M. Synovial sarcoma of the neck: A follow-up study of 24 cases. Cancer 1975;35: 1243-53.

9. Massarelli G, Tanda F, Salis B. Synovial sarcoma of the soft palate: Report of a case. Hum Pathol 1978;9:341-5.

10. Nunez-Alonso C, Gashti EN, Christ ML. Maxillofacial synovial sarcoma: light- and electron-microscopic study of two cases. Am J Surg Pathol 1979;3:23-30.

11. Shmookler BM, Enzinger FM, Brannon RB. Orofacial synovial sarcoma: a clinicopathologic study of 11 new cases and review of the literature. Cancer 1982;50:269-6.
12. Witkin GB, Miettinen M, Rosai J. A biphasic tumor of the mediastinum with features of synovial sarcoma: a report of four cases. Am J Surg Pathol 1989;13:490-499.

13. Brodsky JT, Burt ME, Hajdu SI, Casper ES, Brennan MF. Tendosynovial sarcoma. Cancer 1992;70:484-9.

14. Kashima T, Matsushita H, Kuroda M, Takeuchi H, Udagawa $\mathrm{H}$, Ishida $\mathrm{T}$, et al. Biphasic synovial sarcoma of the peritoneal cavity with $\mathrm{t}(\mathrm{X} ; 18)$ demonstrated by reverse transcriptase polymerase chain reaction. Pathol Int 1997;47:637-41.

15. Snyder M, Batzdorf U, Sparks FC. Unusual malignant tumors involving the brachial plexus: a report of two cases. Am Surg 1979;100:42-8.

16. Cugola L, Pisa R. Synovial sarcoma: with radial nerve involvement. J Hand Surg 1985;10:243-4.

17. Rinehart GC, Mustoe TA, Weeks PM. Management of synovial sarcoma of the median nerve at the elbow. Plast Reconstr Surg 1989;83:528-32.

18. Spielman A, Janzen DL, O'Connell JX, Munk PL. Intraneural synovial sarcoma. Skeletal Radiol 1997;26:677-81.

19. O'Connell JX, Browne WL, Gropper PT, Berean KW. Intraneural biphasic synovial sarcoma: an alternative "glandular" tumor of peripheral nerve. Mod Pathol 1996;9:738-41.

20. Salisbury JR, Isaacson PG. Synovial sarcoma: an immunohistochemical study. J Pathol 1985;147:49-57.

21. Leader M, Patel J, Makin C, Henry K. An analysis of the sensitivity and specificity of the cytokeratin marker CAM 5.2 for epithelial tumours. Results of a study of 203 sarcomas, 50 carcinomas and 28 malignant melanomas. Histopathology 1986;10:1315-24.

22. Wick MR, Swanson PE, Manivel JC. Immunohistochemical analysis of soft tissue sarcomas: Comparisons with electron microscopy. Appl Pathol 1988;6:169-96.

23. Schmidt D, Harms D. The applicability of immunohistochemistry in the diagnosis and differential diagnosis of malignant soft tissue tumors. A reevaluation based on the material of the Kiel Pediatric Tumor Registry. Klin Padiatr 1990; 202:224-9.

24. Schmidt D, Thum P, Harms D, Treuner J. Synovial sarcoma in children and adolescents: a report from the Kiel Pediatric Tumor Registry. Cancer 1991;67:1667-72.

25. Ordonez NG, Mahfouz SM, Mackay B. Synovial sarcoma: an immunohistochemical and ultrastructural study. Hum Pathol 1990;21:733-49.

26. Folpe AL, Schmidt RA, Chapman D, Gown AM. Poorly differentiated synovial sarcoma: immunohistochemical distinction from primitive neuroectodermal tumors and highgrade malignant peripheral nerve sheath tumors. Am J Surg Pathol 1998;22:673-82.

27. Van de Rijn M, Barr FG, Xiong Q-B, Hedges M, Shipley J, Fisher C. Poorly differentiated synovial sarcoma: an analysis of clinical, pathologic and molecular genetic features. Am J Surg Pathol 1999;23:106-12.

28. Hsu S-M, Raine L, Fanger H. Use of avidin-biotin-peroxidase complex $(\mathrm{ABC})$ in immunoperoxidase techniques: A comparison between $\mathrm{ABC}$ and unlabeled antibody (PAP) procedures. J Histochem Cytochem 1981;29:577-80.

29. Erlandson RA, Woodruff JM. Role of electron microscopy in the evaluation of soft tissue neoplasms, with emphasis on spindle cell and pleomorphic tumor. Hum Pathol 1998;29: 1372-81.

30. Ghadially FN. Is synovial sarcoma a carcinosarcoma of connective tissue? Ultrastruct Pathol 1987;11:147-51.

31. Mickelson MR, Brown GA, Maynard JA, Cooper RR, Bonfiglio M. Synovial sarcoma: an electron microscopic study of monophasic and biphasic forms. Cancer 1980;45:2109-18.

32. Gabbiani G, Kaye GI, Lattes R, Majno G. Synovial sarcoma: electron microscopic study of a typical case. Cancer 1971; 28:1031-9. 
33. Argani P, Zakowski MF, Klimstra DS, Rosai J, Ladanyi M. Detection of SYT-SSX chimeric RNA of synovial sarcoma in paraffin-embedded tissue and its application in problematic cases [Published erratum appears in Mod Pathol 1998;11: 592]. Mod Pathol 1998;11:65-71.

34. Noonan KE, Beck C, Holzmayer TA, Chin JE, Wunder JS, Andrulis IL, et al. Quantitative analysis of MDR1 (multidrug resistance) gene expression in human tumors by polymerase chain reaction. Proc Natl Acad Sci U S A 1990;87:7160-4.

35. Smith TA, Machen SK, Fisher C, Goldblum JR. Usefulness of cytokeratin subsets for distinguishing monophasic synovial sarcoma from malignant peripheral nerve sheath tumor. Am J Clin Pathol 1999;112:641-8.

36. Christensen WN, Strong EW, Bains MS, Woodruff JM. Neuroendocrine differentiation in the glandular peripheral nerve sheath tumor: pathologic distinction from the biphasic synovial sarcoma with glands. Am J Surg Pathol 1988;12:41726.

37. Hiraga H, Nojima T, Abe S, Sawa H, Yamashiro K, Yamawaki S, Kaneda K, Nagashima K. Diagnosis of synovial sarcoma with the reverse transcriptase-polymerase chain reaction: analyses of 84 soft tissue and bone tumors. Diagn Mol Pathol 1998;7:102-10.

38. Limon J, Dal Cin P, Sandberg AA. Translocations involving the $\mathrm{X}$ chromosome in solid tumors: presentation of two sarcomas with $t((X ; 18)(q 13 ; p 11)$. Cancer Genet Cytogenet 1986;23:87-91.

39. Griffin CA, Emanuel BS. Translocation $(X ; 18)$ in a synovial sarcoma. Cancer Genet Cytogenet 1987;26:181-3.

40. Smith S, Reeves BR, Wong L, Fisher C. A consistent chromosome translocation in synovial sarcoma. Cancer Genet Cytogenet 1987;26:179-80.

41. Turc-Carel C, Dal Cin P, Limon J, Rao U, Li FP, Corson JM, et al. Involvement of chromosome $\mathrm{X}$ in primary cytogenetic change in human neoplasia: nonrandom translocation in synovial sarcoma. Proc Natl Acad Sci U S A 1987;84:1981-5.

42. Ueda T, Aozasa K, Tsujimoto M, Uchida A, Taniwaki M, Abe T. Translocation X;18 and insertion $15 ; 11$ in a case of synovial sarcoma. Cancer Genet Cytogenet 1988;30:183-5.

43. Limon J, Mrozek K, Nedoszytko B, Babinska M, Jaskiewicz J, Kopacz A, et al. Cytogenetic findings in two synovial sarcomas. Cancer Genet Cytogenet 1989;38:215-22.

44. Noguera R, Lopez-Gines C, Gil R, Carda C, Pellin A, Llombart-Bosch A. Translocation $(\mathrm{X} ; 18)$ in a synovial sarcoma: A new case. Cancer Genet Cytogenet 1998;33:311-2.

45. Sreekantaiah C, Ladanyi M, Rodriguez E, Chaganti RSK. Chromosomal aberrations in soft tissue tumors: relevance to diagnosis, classification, and molecular mechanisms. Am J Pathol 1994;144:1121-34.

46. Mazzella F, Johnson C, Tallini G, Crotty PL. Lack of expression of SYT-SSX1 mRNA in spindle cell sarcoma other than synovial sarcoma. [abstract] Lab Invest 1996;74:10.

47. Balazs L, Parham D, Shurtleff S, Pappo A, Downing J. Identification of the $\mathrm{t}(\mathrm{X}: 18)$ as a diagnostic tool in the differential diagnosis of synovial sarcomas versus peripheral nerve sheath tumors. [abstract] Mod Pathol 1997;10:8.

48. Lasota J, Jasinski M, Debiec-Rychter M, Szadowska A, Limon J, Miettinen M. Detection of the SYT-SSX fusion transcripts in formaldehyde-fixed, paraffin-embedded tissue: A reverse transcription polymerase chain reaction amplification assay useful in the diagnosis of synovial sarcoma. Mod Pathol 1998;11:626-33.

49. Van de Rijn M, Barr FG, Collins MH, Xiong Q-B, Fisher C. Absence of SYT-SSX fusion products in soft tissue tumors other than synovial sarcoma. Am J Clin Pathol 1999;112: 43-9.

50. Woodruff JM. Pathology of the major peripheral nerve sheath neoplasms. Monogr Pathol 1996;38:129-61.

51. Vang R, Biddle DA, Harrison WR, Heck K, Cooley LD. Malignant peripheral nerve sheath tumor with a $t(X ; 18)$. A synovial sarcoma variant? Arch Pathol Lab Med 2000;124:864-7.

52. Ordi J, de Alava E, Torné A, Mellado B, Pardo-Mindan J, Iglesias $\mathrm{X}$, et al. Intraabdominal desmoplastic small round cell tumor with EWS/ERG fusion transcript. Am J Surg Pathol 1998;22:1026-32.

53. Burchill SA, Wheeldon J, Cullinane C, Lewis IJ. EWS-FLI1 fusion transcripts identified in patients with typical neuroblastoma. Eur J Cancer 1997;33:239-43.

54. Thorner P, Squire J, Chilton-McNeill S, Marrano P, Bayani J, Malkin D, et al. Is the EWS/FLI-1 fusion transcript specific for Ewing sarcoma and peripheral primitive neuroectodermal tumor? A report of four cases showing this transcript in a wider range of tumor types. Am J Pathol 1996;148:1125-38.

55. McComb EN, McComb RD, DeBoer JM, Neff JR, Bridge JA. Cytogenetic analysis of a malignant Triton tumor and a malignant peripheral nerve sheath tumor and a review of the literature. Cancer Genet Cytogenet 1996;91:8-12.

56. Mitelman F. Catalog of chromosome aberrations in cancer. 4th ed. New York: Wiley-Liss; 1991.

57. Travis JA, Sandberg AA, Neff JR, Bridge JA. Cytogenetic findings in malignant Triton tumor. Genes Chromosom Cancer 1994;9:1-7.

58. Riccardi VM, Elder DW. Multiple cytogenetic aberrations in neurofibrosarcomas complicating neurofibromatosis. Cancer Genet Cytogenet 1986;23:199-209.

59. Jhanwar SC, Chen Q, Li FP, Brennan MF, Woodruff JM. Cytogenetic analysis of soft tissue sarcomas: Recurrent chromosome abnormalities in malignant peripheral nerve sheath tumors (MPNST). Cancer Genet Cytogenet 1994;78:138-44.

60. Sorensen PHB, Triche TJ. Gene fusions encoding chimaeric transcription factors in solid tumours. Semin Cancer Biol 1996;7:3-14.

61. Van Kessel AG, de Bruijn D, Hermsen L, Janssen I, dos Santos $\mathrm{NR}$, Willems R, et al. Masked $\mathrm{t}(\mathrm{X} ; 18)(\mathrm{p} 11 ; \mathrm{q} 11)$ in a biphasic synovial sarcoma revealed by FISH and RT-PCR. Genes Chromosom Cancer 1998;23:198-201.

62. Nagao K, Ito H, Yoshida H. Chromosomal translocation $t(X$; 18) in human synovial sarcomas analyzed by fluorescence in situ hybridization using paraffin-embedded tissue. Am J Pathol 1996;148:601-9.

63. Noguera R, Navarro S, Cremades A, Rosello-Sastre E, Pellin A, Peydro-Olaya A, et al. Translocation $(\mathrm{X} ; 18)$ in a biphasic synovial sarcoma with morphologic features of neural differentiation. Diagn Mol Pathol 1998;7:16-23.

64. Mandahl N, Heim S, Arheden K, Rydholm A, Willen H, Mitelman F. Multiple karyotypic rearrangements, including $t(X ;$ 18)(p11; q11), in a fibrosarcoma. Cancer Genet Cytogenet 1988;30:323-327.

65. Sandberg AA. The chromosomes in human cancer and leukemia. 2nd ed. New York: Elsevier; 1990. p. 945-7. 